\title{
Basal Cell Carcinoma Originating in a Tattoo: Case Report and Review of an Uncommon Complication in Tattoo Recipients
}

\author{
Boya Abudu ${ }^{1}$, Christof P. Erickson ${ }^{2}$, Antoanella Calame ${ }^{2}$, Philip R. Cohen ${ }^{3,4}$
}

\author{
1 University of California San Diego School of Medicine, La Jolla, CA, USA \\ 2 Dermatology, Compass Dermatopathology, San Diego, CA, USA \\ 3 San Diego Family Dermatology, National City, CA, USA \\ 4 Touro University California College of Osteopathic Medicine, Vallejo, CA, USA
}

Key words: basal cell carcinoma, tattoo, immunocompromised district, pigment, skin cancer

Citation: Abudu B, Erickson CP, Calame A, Cohen PR. Basal cell carcinoma originating in a tattoo: case report and review of an uncommon complication in tattoo recipients. Dermatol Pract Concept. 2019;9(4):265-270. DOI: https://doi.org/10.5826/dpc.0904a03

Accepted: July 17, 2019; Published: October 31, 2019

Copyright: (2019 Abudu et al. This is an open-access article distributed under the terms of the Creative Commons Attribution License, which permits unrestricted use, distribution, and reproduction in any medium, provided the original author and source are credited.

Funding: None.

Competing interests: The authors have no conflicts of interest to disclose.

Authorship: All authors have contributed significantly to this publication.

Corresponding author: Boya Abudu, MPH, University of California San Diego School of Medicine, La Jolla, CA 92093. Email: boyaabudu30@gmail.com

ABSTRACT Background: The placement of a tattoo is a common event. Basal cell carcinoma arising from a tattoo is rare despite this neoplasm being the most common form of skin cancer.

Objective: We describe a 41-year-old man who developed a basal cell carcinoma in his tattoo and review the literature of basal cell carcinomas originating in a tattoo.

Methods: A literature search using PubMed was performed. The following terms were searched: "basal," "carcinoma," "cell," and "tattoo." The characteristics of individuals with a basal cell carcinoma originating in a tattoo were analyzed and summarized.

Results: A total of 13 patients ( 6 women and 7 men) with a basal cell carcinoma arising in a tattoo have been reported. The majority of the tumors were located on the head ( 6 cases, $46.2 \%$ ) followed by either an upper extremity ( 4 cases, $30.7 \%$ ) or the trunk ( 3 cases, $23.1 \%$ ). Most of the carcinomas were asymptomatic; however, 2 patients reported pruritus associated with their tumor. Nodular basal cell carcinoma was the most common subtype diagnosed ( 5 tumors), followed by superficial basal cell carcinoma (2 tumors). One patient had either a pagetoid or a mixed (nodular and sclerosing) histology. The pathological variant was not described for 4 patients.

Conclusions: Basal cell carcinoma arising in a tattoo is a rare occurrence. Although this occurrence may be coincidental, emerging evidence of carcinogenesis associated with tattoo pigment may suggest a causal link. Elucidating this important relationship warrants further investigation. 

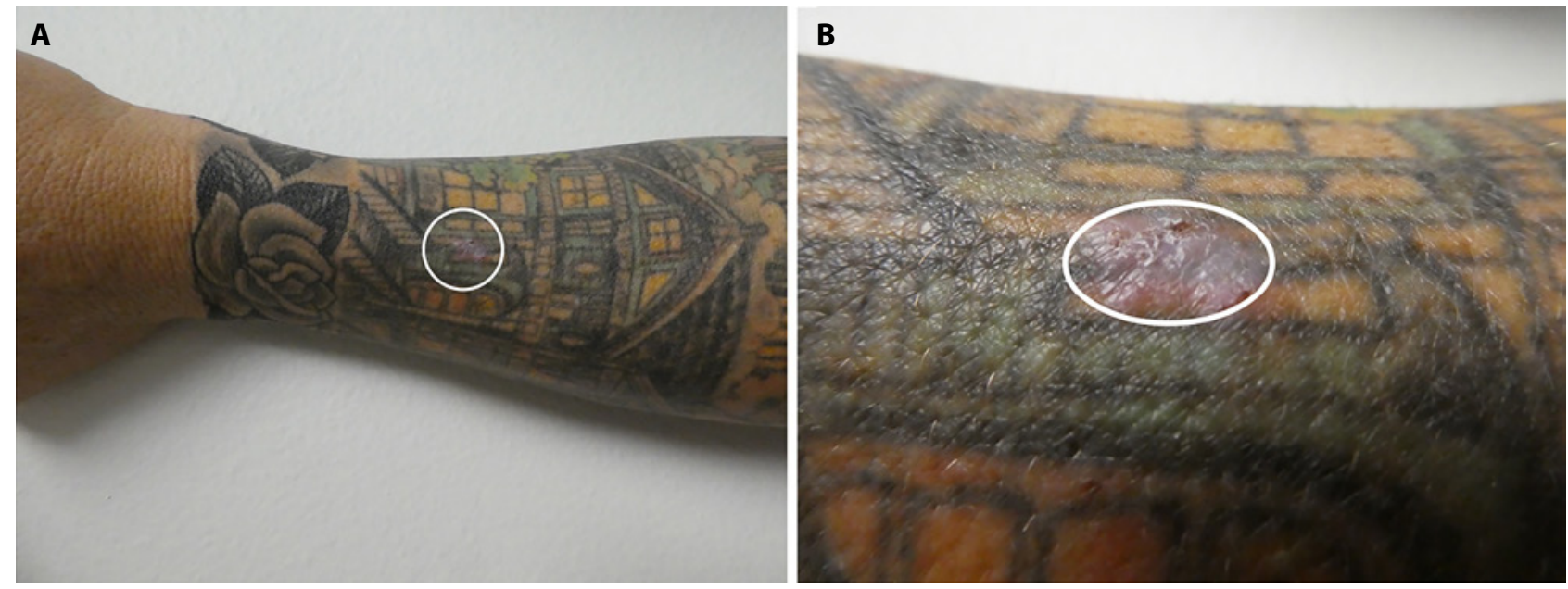

Figure 1. Distant (A) and closer (B) views of a nodular basal cell carcinoma (within the white circle) presenting as a red plaque within the green tattoo on the left forearm of a 41-year-old man. [Copyright: (O2019 Abudu et al.]

\section{Introduction}

Basal cell carcinoma is the most common form of skin cancer [1]. Tattooing has become a frequent occurrence; it is estimated that $25 \%$ of individuals aged 18 to 50 years have at least 1 tattoo [2]. The development of basal cell carcinoma in a tattoo is uncommon. We describe a man whose basal cell carcinoma developed within his tattoo. We also review the previously published individuals in whom this occurred.

\section{Case Report}

A 41-year-old Caucasian man presented for evaluation of a new lesion on his left arm. He had a tattoo placed on his arm when he was 29 years old. Ten months before presenting for evaluation, he noticed a red lesion appearing within his tattoo. The lesion was asymptomatic but continued to increase in size.

Cutaneous examination revealed a confluent tattoo occupying his left arm and forearm. Within the green portion of the tattoo, there was an erythematous $15 \times 7 \mathrm{~mm}$ red and brown plaque on his distal forearm (Figure 1). There was no palpable axillary lymphadenopathy. A punch biopsy was performed.

Microscopic evaluation of the biopsy specimen showed nodular aggregates of basaloid tumor cells extending from the epidermis into the underlying dermis. There was palisading of the cells at the periphery of the tumor nodules. There was retraction of the dermal stroma from the periphery of the basal tumor cells. A large deposition of mucin was present within 1 of the tumor nodules. In addition, there were small black amorphous particles not only adjacent to the tumor, but also throughout the dermis (Figure 2).

The tumor was a nodular basal cell carcinoma. The black pigmented particles were the green tattoo. Correlation of the clinical presentation and pathology findings established a diagnosis of a basal cell carcinoma arising in tattooed skin.

The residual basal cell carcinoma was excised. The tumor was cleared after 2 stages of Mohs micrographic surgery. The residual defect was repaired with a layered closure (Figure 3). There was no recurrence at follow-up examination.

\section{Review}

\section{History}

The first report of a basal cell carcinoma originating at the site of a tattoo was described in 1976 [3]. Bashir reported 2 patients: a 60-year-old woman and a 52-year-old man. Both patients developed new lesions within tattoos that had been present for 15 to 20 years on the temporal scalp.

Since then, including our patient, only 11 individuals with a basal cell carcinoma arising in tattoos have been reported (Table 1) [3-11]. We describe a man whose basal cell carcinoma appeared in his tattoo and also provide a comprehensive review of the features of the patients with basal cell carcinoma originating in a tattoo.

\section{Epidemiology}

Basal cell carcinoma originating in a tattoo has been described in 13 patients (Tables 2 and 3). This includes 6 women ranging in age from 28 to 86 years (median, 62 years). It also includes 7 men ranging in age from 35 to 76 years (median, 52 years).

The duration between application of the tattoo and discovery of the basal cell carcinoma among all patients ranged from 1 to 57.5 years (median, 14 years). In women, the duration ranged from 5 to 30 years (median, 13 years). In men, the duration ranged from 1 to 57.5 years (median, 15 years).

The majority of patients in whom a basal cell carcinoma originated in a tattoo were Caucasian (7 of 8 individuals, 

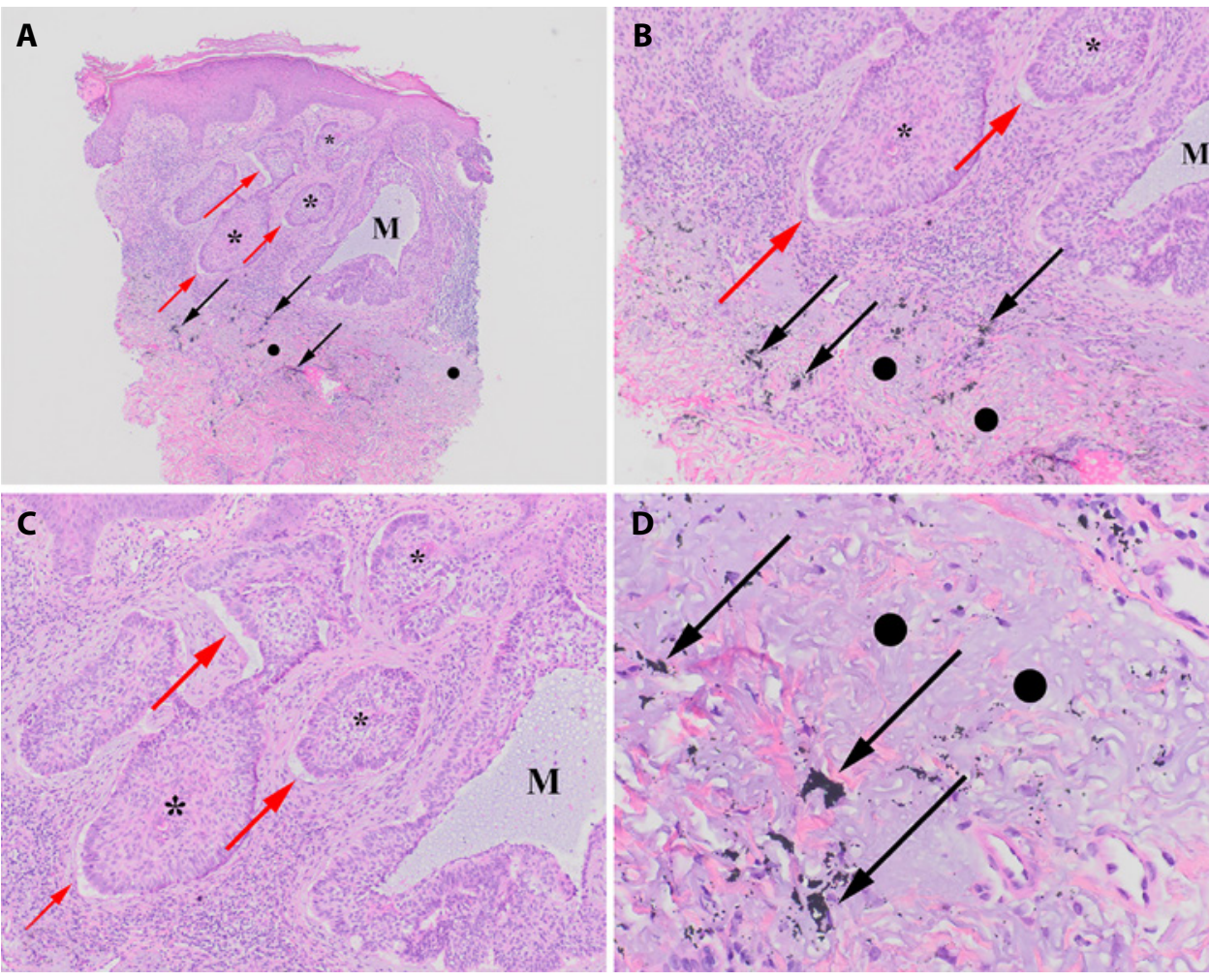

Figure 2. Pathological features of a nodular basal cell carcinoma arising in a tattoo from the left forearm of a 41-year-old man. Low (A), medium (B and $\mathrm{C})$, and high (D) magnification views show nodular aggregates of basaloid tumor cells (asterisks) extending from the epidermis into the dermis. Mucin is present in a tumor nodule (M) and there is retraction of the dermal stroma from the palisading cells at the periphery of the tumor nodules (red arrows). Black, amorphous pigment (representing the green tattoo) is also present not only around the tumor but also in the dermis (black arrows). There is solar elastosis in the dermis (black circles) (H\&E: A, ×4; B, ×10; C, ×20; D, $\times 40$ ). [Copyright: (O2019 Abudu et al.]
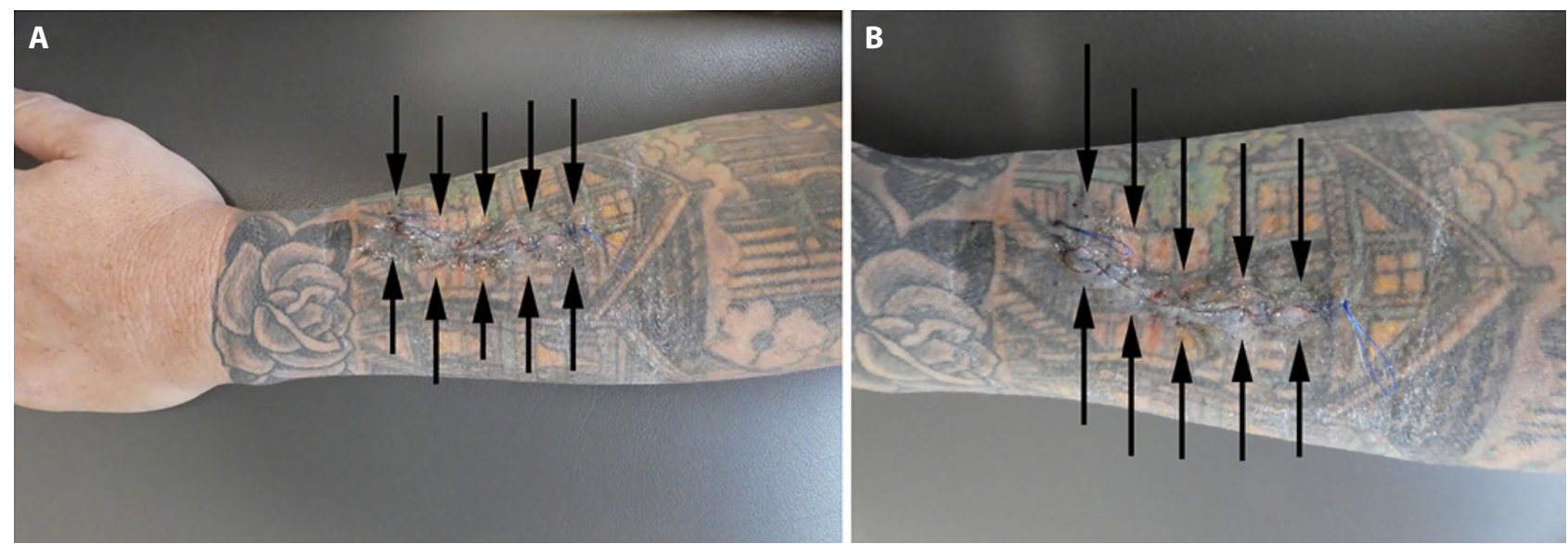

Figure 3. Appearance of the tattooed left forearm following the Mohs micrographic surgery that removed the basal cell carcinoma. Distant (A) and closer (B) views of the left forearm after a layered closure (between black arrows) was used to close the surgical defect following complete removal of the tumor. [Copyright: (2019 Abudu et al.]

$87.5 \%$ ). One woman was of East Asian origin (1 of 8 individuals, $12.5 \%$ ). The race was not described in 5 of the patients.

\section{Symptoms}

Most of the patients (11 of 13 individuals, 84.6\%) were asymptomatic at presentation. However, 2 of the patients had pruritus localized to their tumor $[6,8]$. One of the patients developed pruritus 5 years after tattoo placement on his back [8].

\section{Clinical Presentation}

The color of the basal cell carcinoma ranged from red $(2$ patients) to brown ( 2 patients) to skin-colored ( 1 patient) in
4 patients. The color of the tumor was not described for 9 of the patients.

In 4 individuals, the basal cell carcinoma presented as an ulcer or an ulcerated lesion. The tumor presented as a nodule or a nodular plaque in 3 patients. Two patients presented with a papule and 2 patients presented with a plaque. One woman presented with a cystic lesion on her eyelid [11]. The morphology was not described in 1 of the patients.

The size of the basal cell carcinoma was described for 7 individuals. Five women had a basal cell carcinoma that ranged in size from 6 to $20 \mathrm{~mm}$ (median, $10 \mathrm{~mm}$ ). Two men had a basal cell carcinoma that ranged in size from 7 to 15 $\mathrm{mm}$ (median, $11 \mathrm{~mm}$ ). 
Table 1. Publications Describing the Significance of Basal Cell Carcinoma Arising in a Tattoo Author, Year [Ref] Contribution

\begin{tabular}{|l|l|}
\hline Bashir, 1976 [3] & $\begin{array}{l}\text { The first reports of a BCC arising in a tattoo; on the temple of a woman and on the } \\
\text { temple of a man. }\end{array}$ \\
\hline Earley, 1983 [4] & $\begin{array}{l}\text { The first report of a BCC arising in a red tattoo on the shoulder of a man. They also } \\
\text { reported a BCC arising on the hand of a man. }\end{array}$ \\
\hline Wiener and Scher, 1987 [5] & The first report of a BCC arising in a blue and green tattoo on the forearm of a man. \\
\hline Doumat et al, 2004 [6] & The youngest man with a BCC arising in a tattoo. \\
\hline Birnie et al, 2006 [7] & The youngest patient with a BCC arising in a tattoo on the back of a woman. \\
\hline Kluger et al, 2008 [8] & $\begin{array}{l}\text { A BCC arising in a tattoo on a man with a personal history of skin cancer } \\
\text { (melanoma). The BCC was found on his back. }\end{array}$ \\
\hline Lee et al, 2009 [9] & $\begin{array}{l}\text { A BCC arising in a tattoo of an individual of East Asian origin whose lesion appeared } \\
\text { on her eyebrow. }\end{array}$ \\
\hline $\begin{array}{l}\text { Omidian and Emad-Mostofi, } \\
2009 \text { [10] }\end{array}$ & $\begin{array}{l}\text { The largest BCC arising from a tattoo on the upper lip of a woman. A second woman } \\
\text { with a crusted nodular BCC arising in a tattoo on her upper lip was also described. }\end{array}$ \\
\hline Messmer et al, 2018 [11] & $\begin{array}{l}\text { The BCC on the lower eyelid of a woman was of mixed histology: nodular and } \\
\text { sclerosing. She was also the oldest patient with a BCC originating in a tattoo. }\end{array}$ \\
\hline Abudu et al, 2019 [current study] & $\begin{array}{l}\text { A nodular BCC arising in a green tattoo on the forearm of a man was described and a } \\
\text { comprehensive review of all BCCs originating in a tattoo was performed. }\end{array}$ \\
\hline
\end{tabular}

$\mathrm{BCC}=$ basal cell carcinoma; Ref $=$ reference .

Table 2. Clinical Characteristics of 6 Women With Basal Cell Carcinoma Arising in a Tattoo

\begin{tabular}{|c|c|c|c|c|c|c|c|c|c|}
\hline C & $A, R$ & Dur & Site & Size; Color & Morphology & Histology & $\begin{array}{c}\text { Tattoo } \\
\text { Pigment }\end{array}$ & Tx & Ref \\
\hline 1 & $28, \mathrm{Ca}$ & 6 & $\begin{array}{l}\text { Central } \\
\text { back }\end{array}$ & $6 \mathrm{~mm}$; pearly & Nodule & Nodular & Black & Ex & [7] \\
\hline 2 & $60, \mathrm{NS}$ & 20 & Temple & $7-8 \mathrm{~mm}$; NS & Ulcer & NOS & Black & Ex & [3], C1 \\
\hline 3 & $60, \mathrm{EA}$ & 5 & Eyebrow & $\begin{array}{l}10 \times 13 \mathrm{~mm} ; \\
\text { skin-colored and } \\
\text { translucent }\end{array}$ & Papule & Nodular & Black & MMS & [9] \\
\hline 4 & $64, \mathrm{Ca}$ & 30 & Upper lip & $10 \times 10 \mathrm{~mm} ; \mathrm{NS}$ & $\begin{array}{l}\text { Crusting } \\
\text { nodular plaque }\end{array}$ & Nodular & Blue & NS & [10], C2 \\
\hline 5 & $72, \mathrm{Ca}$ & NS & Upper lip & $\begin{array}{l}20 \times 20 \mathrm{~mm} ; \\
\text { brown and red }\end{array}$ & $\begin{array}{l}\text { Pedunculated, } \\
\text { umbrella- } \\
\text { shaped plaque }\end{array}$ & Nodular & $\begin{array}{l}\text { Black, } \\
\text { blue }\end{array}$ & NS & [10], C1 \\
\hline 6 & $86, \mathrm{Ca}$ & 13 & $\begin{array}{l}\text { L lower } \\
\text { eyelid }\end{array}$ & NS; NS & Cystic lesion & $\begin{array}{l}\text { Nodular and } \\
\text { sclerosing }\end{array}$ & $\begin{array}{l}\text { Black, } \\
\text { turquoise }\end{array}$ & Ex & {$[11]$} \\
\hline
\end{tabular}

$\mathrm{A}=$ age (years); $\mathrm{C}=$ case; $\mathrm{Ca}=$ Caucasian; Dur = duration of tattoo (years); EA = East Asian; Ex = excision; $\mathrm{L}=$ left $\mathrm{MMS}=$ Mohs micrographic surgery; NOS = not otherwise specified (basal cell carcinoma); NS = not stated; $\mathrm{R}=$ race; Ref = reference; $\mathrm{Tx}=$ treatment.

The basal cell carcinoma within a tattoo often occurred in sun-exposed areas of the head or upper extremity (Table 4). Indeed, the most common location of tattoo-associated basal cell carcinoma was the head ( 6 patients, $46.2 \%$ ) followed by an upper extremity (4 patients, $30.7 \%$ ) and trunk (3 patients, $23.1 \%)$. In women, the most common location was the face ( 5 of 6 patients, $83.3 \%$ ). In men, the most common location was an upper extremity ( 4 of 7 patients, $57.1 \%$ ).

\section{Dermoscopy}

Dermoscopy was not reported in any of the individuals with basal cell carcinoma in a tattoo. We suspect that the dermoscopy of basal cell carcinoma originating from tattoos would have the same patterns as those occurring on tattoo-free skin: arborizing vessels, telangiectasias, blue-gray ovoid nests, globules, and ulceration [12]. In addition, dermoscopic features of a tattoo might be noted: a nonspecific homogenous pattern with nonsharp borders at the periphery [13]. 
Table 3. Clinical Characteristics of 7 Men With Basal Cell Carcinoma Arising in a Tattoo

\begin{tabular}{|c|c|c|c|c|c|c|c|c|c|}
\hline C & $A, R$ & Dur & Site & Size; Color & Morphology & Histology & $\begin{array}{c}\text { Tattoo } \\
\text { Pigment }\end{array}$ & Tx & Ref \\
\hline 1 & $35, \mathrm{NS}$ & 1 & L scapula & $7 \mathrm{~mm}$; NS & $\begin{array}{l}\text { Infiltrated } \\
\text { papule }\end{array}$ & Pagetoid & NS & Ex & [6] \\
\hline 2 & $40, \mathrm{Ca}$ & 7 & Back & NS; NS & NS & Superficial & Blue & Ex & [8] \\
\hline 3 & $41, \mathrm{Ca}$ & 12 & L forearm & $\begin{array}{l}15 \times 7 \mathrm{~mm} \text {; red } \\
\text { and brown }\end{array}$ & Plaque & Nodular & NS & MMS & CR \\
\hline 4 & $52, \mathrm{NS}$ & 15 & Temple & NS; NS & Ulcerated lesion & NOS & Black & Ex & [3], C2 \\
\hline 5 & $64, \mathrm{NS}$ & 40 & $\mathrm{R}$ hand & NS; NS & Ulcer & NOS & Black & $\mathrm{Ex}$ & [4], C2 \\
\hline 6 & 64, Ca & 46 & $\mathrm{~L}$ arm & NS; NS & Pearly nodule & NOS & $\begin{array}{l}\text { Blue and } \\
\text { green }\end{array}$ & NS & [5] \\
\hline 7 & $76, \mathrm{NS}$ & 57.5 & Shoulder & NS; NS & Ulcerated lesion & Superficial & Red & Ex & [4], C1 \\
\hline
\end{tabular}

$\mathrm{A}=$ age (years); $\mathrm{C}=$ case; $\mathrm{Ca}=$ Caucasian; $\mathrm{CR}=$ current report; Dur = duration of tattoo (years); Ex = excision; $\mathrm{L}=$ left; MMS = Mohs micrographic surgery; NOS = not otherwise specified (basal cell carcinoma); NS = not stated; $\mathrm{R}=$ race; Ref = reference; $\mathrm{R}$ = right; $\mathrm{Tx}=$ treatment.

\section{Pathology}

The most common pathological variant of basal cell carcinoma was nodular in 5 patients: 4 women and 1 man. Superficial ( 2 men) and mixed (nodular and sclerosing, 1 woman) basal cell carcinomas were also observed, yet less frequently. One man's tumor was described as pagetoid. The pathological variant was not described in 4 patients.

In addition, all of the tissue specimens documented amorphous particles in the dermis. These particles represented the tattoo pigment. This pigment was most frequently observed perivascularly in the upper dermis.

\section{Tattoo Color}

Basal cell carcinomas most commonly originated in black tattoos (7 patients, $53.8 \%$ ). Some of the basal cell carcinomas originated in blue ( 4 patients, $30.8 \%$ ), turquoise (1 patient, $7.7 \%$ ), or red (1 patient, $7.7 \%$ ) tattoos. Three of the patients' tumors appeared within tattoos of 2 colors: black and blue (1 patient, $7.7 \%$ ), black and turquoise ( 1 patient, $7.7 \%$ ), and blue and green (1 patient, $7.7 \%$ ). The color of the tattoo in which the basal cell carcinoma developed was not described for 3 patients.

\section{Treatment}

The basal cell carcinoma was excised in 9 patients; 2 of these patients were treated with Mohs micrographic surgery. The management was not described in the other 4 patients. The biological behavior of a basal cell carcinoma originating in a tattoo appears to be similar to that of basal cell carcinoma on tattoo-free skin. The prognosis for individuals with tattoo-associated basal cell carcinoma is excellent; all of the patients did well after removal of their tumor and experienced no recurrence.
Table 4. Location of Basal Cell Carcinoma in a Tattoo

\begin{tabular}{|l|c|c|c|} 
& Women (n, \%) & Men (n, \%) & Total (n, \%) \\
\hline Head & $5(38.5 \%)$ & $1(7.7 \%)$ & $6(46.2 \%)$ \\
\hline $\begin{array}{l}\text { Upper } \\
\text { extremity }\end{array}$ & $0(0 \%)$ & $4(30.7 \%)$ & $4(30.7 \%)$ \\
\hline Trunk & $1(7.7 \%)$ & $2(15.4 \%)$ & $3(23.1 \%)$ \\
\hline Total & $6(46.2 \%)$ & $7(53.8 \%)$ & $13(100 \%)$ \\
\hline
\end{tabular}

\section{Pathogenesis}

Several adverse events have been documented to occur with tattoos, including reactive dermatoses, infections, and neoplasms [14]. In addition to basal cell carcinoma, other neoplasms that have appeared in tattoos include dermatofibrosarcoma protuberans, keratoacanthoma, leiomyosarcoma, melanoma, and squamous cell carcinoma. [15-17]. Whether the appearance of these tumors is a serendipitous occurrence or related to tattoo-induced carcinogenesis remains to be definitively established.

The possibility of the coincidental appearance of a basal cell carcinoma developing in a tattoo has been proposed. Because the prevalence of tattoos is increasing, the likelihood of detecting a basal cell carcinoma at the site of a tattoo would also be expected to increase. However, the incidence of basal cell carcinoma originating in a tattoo is still rare relative to the increasing population of tattooed individuals [8].

An immunocompromised district describes an area of the skin that is more vulnerable to other dermatoses as compared with the rest of the body $[18,19]$. Local immune dysregulation-of variable etiologies-results in an immunocompromised district; the immune aberration can be genetic or acquired. The etiology of an acquired immunocompromised 
district includes herpetic infections, ionizing or ultraviolet radiation, tattoos, and trauma. Cutaneous exposure to these etiological factors increases the risk for immune destabilization at the affected site and subsequent development of another cutaneous disorder such as infection or neoplasm [20]. Therefore, the appearance of a basal cell carcinoma in a tattoo may represent the development of the tumor in a tattoo-related immunocompromised district.

Many investigators consider the occurrence of skin cancer, particularly basal cell carcinoma, to be etiologically related to tattoos [21]. Industrial compounds such as azo pigments and polycyclic compounds are common tattoo agents. These compounds are thought to have carcinogenic potential.

Azo pigments are a popular choice because of their durability, longevity, and color intensity; however, they have been associated with carcinogenesis in promoting basal cell carcinoma [21]. Polycyclic aromatic hydrocarbons are frequently used with carbon in black tattoos. Several in vitro studies of polycyclic aromatic hydrocarbons have supported the risk for carcinogenesis and mutagenesis when absorption of ultraviolet radiation results in the release of reactive oxygen species [22,23].

There is some evidence that ultraviolet radiation may lead to pigment decomposition; the byproducts may be toxic to the skin [24,25]. The extent to which skin metabolizes tattoo pigment remains unclear [26,27]. The appearance of most neoplasms in sun-exposed areas strengthens the evidence for this etiological relationship.

\section{Conclusions}

The development of basal cell carcinoma in a tattoo is a rare occurrence that has been described in only 13 individuals. The majority of the tumors occurred in sun-exposed areas containing black pigment. The length of time between tattoo placement and tumor onset varied from 1 to 57.5 years. Further studies are needed to investigate the role of pigment toxicology and skin metabolism for insight into the causal link between basal cell carcinoma and tattoos.

\section{References}

1. Lomas A, Leonardi-Bee J, Bath-Hextall F. A systematic review of worldwide incidence of nonmelanoma skin cancer. $\mathrm{Br} J$ Dermatol. 2012;166(5):1069-1080.

2. Laumann AE, Derick AJ. Tattoos and body piercings in the United States: a national data set. J Am Acad Dermatol. 2006;55(3):413-421.

3. Bashir AH. Basal cell carcinoma in tattoos: report of two cases. Br J Plast Surg. 1976;29(4):288-290.

4. Earley MJ. Basal cell carcinoma arising in tattoos: a clinical report of two cases. Br J Plast Surg. 1983;36(2):258-259.

5. Wiener DA, Scher RK. Basal cell carcinoma arising in a tattoo. Cutis. 1987;39(2):125-126.

6. Doumat F, Kaise W, Barbaud A, Schmutz JL. Basal cell carcinoma in a tattoo. Dermatology. 2004;208(2):181-182.
7. Birnie AJ, Kulkarni K, Varma S. Basal cell carcinoma arising in a tattoo. Clin Exp Dermatol. 2006;31(6):820-821.

8. Kluger N, Phan A, Debarbieux S, Balme B, Thomas L. Skin cancers arising in tattoos: coincidental or not? Dermatology. 2008;217(3):219-221.

9. Lee JS, Park J, Kim SM, Yun SK, Kim HU. Basal cell carcinoma arising in a tattooed eyebrow. Ann Dermatol. 2009;21(3):281284.

10. Omidian M, Emad-Mostofi N. Basal cell carcinoma arising from traditional tattoo. Arch Iran Med. 2009;12(2):198.

11. Messmer EM, Möhring-Bengisu C, Miller C. Lidline tattoo associated with basal cell carcinoma of the lid margin-coincidence or association? [in German; abstract in English, German]. Klin Monbl Augenheilkd. 2018;235(7):785-788.

12. Lallas A, Apalla Z, Ioannides D, et al. Dermoscopy in the diagnosis and management of basal cell carcinoma. Future Oncol. 2015;11(22):2975-2984.

13. Kendel M, Toncic RJ, Bradamante M, et al. Dermoscopy of a tattoo pseudolymphoma. Dermatol Pract Concept. 2019;9(1):17-19.

14. Kluger N. Acute complications of tattooing presenting in the ED. Am J Emerg Med. 2012;30(9):2055-2063.

15. Basu P, Erickson CP, Calame A, Cohen PR. Osteoma cutis: an adverse event following tattoo placement. Cureus. 2019;11(3):e4323.

16. Paprottka FJ, Krezdorn N, Narwan M, et al. Trendy tattoosmaybe a serious health risk? Aesthetic Plast Surg. 2018;42(1):310321.

17. Kluger N, Koljonen V. Tattoos, inks, and cancer. Lancet Oncol. 2012;13(4):e161-e168.

18. Ruocco V, Ruocco E, Piccolo V, Brunetti G, Guerrera LP, Wolf $\mathrm{R}$. The immunocompromised district in dermatology: a unifying pathogenic view of the regional immune dysregulation. Clin Dermatol. 2014;32(5):569-576.

19. Cohen PR. Zosteriform impetigo: Wolf's isotopic response in a cutaneous immunocompromised district. Dermatol Pract Concept. 2015;5(3):35-39.

20. Ruocco V, Brunetti G, Puca RV, Ruocco E. The immunocompromised district: a unifying concept for lymphoedematous, herpes-infected and otherwise damaged sites. J Eur Acad Dermatol Venereol. 2009;23(12):1364-1373.

21. Engel E, Ulrich H, Vasold R, et al. Azo pigments and a basal cell carcinoma at the thumb. Dermatology. 2008;216(1):76-80.

22. Regensburger J, Lehner K, Maisch T, et al. Tattoo inks contain polycyclic aromatic hydrocarbons that additionally generate deleterious singlet oxygen. Exp Dermatol. 2010;19(8):e275-e281.

23. Laux P, Tralau T, Tentschert J, et al. A medical-toxicological view of tattooing. Lancet. 2016;387(10016):395-402.

24. Engel E, Spannberger A, Vasold R, Konig B, Landthaler M, Baumler W. Photochemical cleavage of a tattoo pigment by UVB radiation or natural sunlight. J Dtsch Dermatol Ges. 2007;5(7):583589.

25. Engel E, Vasold R, Santarelli F, et al. Tattooing of skin results in transportation and light-induced decomposition of tattoo pigments-a first quantification in vivo using a mouse model. Exp Dermatol. 2010;19(1):54-60.

26. Cui Y, Churchwell MI, Couch LH, Doerge DR, Howard PC. Metabolism of pigment yellow 74 by rat and human microsomal proteins. Drug Metab Dispos. 2005;33(10):1459-1465.

27. Engel E, Santarelli F, Vasold R, et al. Modern tattoos cause high concentrations of hazardous pigments in skin. Contact Dermatitis. 2008;58(4):228-233. 